\title{
CORRESPONDENCE
}

\section{Man versus tsetse}

SIR - I must contend with your leading article "Fighting tsetse flies and people" (Nature 2 July, p.1).

In it you state that the eradication of the tsetse fly in certain parts of Africa (by such organizations as ILRAD) would be a revolutionary advancement for its people. Cattle would then be able to graze over a much larger area of land, so more food would result.

This, in itself, is quite true - for man. But the tsetse fly is one of the last remaining barriers against mankind's inevitable destruction of the natural habitats for literally millions of animals of the continent. Would not this "advancement" seal the fate of these millions?

Animals in the wild cannot compete with organized grazing. It's like asking one man to stop a moving steamroller by standing in front of it - he would be crushed. The question is: do we have the right to do this, to crush other forms of life?

As the most powerful animal on this planet, man is entrusted with a duty to preserve that which cannot defend itself. Although the African lion is strong, it can't stop a steamroller.

Jamesville,

ADAM J. Becker

New York, USA

\section{Author - Anon}

SIR - Drs Gillman and Lichtigfeld (Nature 25 June, p.608) suggest that the present system of assessment of scientific papers is endangered by a cabal of corrupt referees, and propose a completely open system. Referees may be prejudiced and incompetent but they are not a secret society. Vigilant editorial control rather than public exposure seems the most appropriate way to eliminate bad referees.

Since referees may be influenced by the known standing of the author or the author's institute, I propose that the anonymity afforded to referees should be extended to authors. If papers were submitted with the author's name, address and

acknowledgements on separate sheets of paper and these were retained by the editor when the manuscript was forwarded to the referees, conscious or unconscious bias would be avoided.

Royal Free Hospital,

London NW3, UK

\section{From the museum}

SIR - We should like to explain a matter that puzzled you in your editorial of 2 July (p.1): the place of cladistics in the exhibition policy of the British Museum (Natural History).

Exhibitions have a general tendency to conceal background controversy ${ }^{1}$. This should not be seen as a conspiracy on the part of designers but is, in fact, a phenomenon that is apparent in the majority of educational media. Every lecturer or textbook writer has to decide the extent to which he will emphasize a straightforward story at the expense of alternative views. The emphasis chosen depends on the circumstances; the less knowledgeable the audience, the less appropriate it is to elaborate the story. Knowing how to make this choice is particularly difficult in exhibitions since the limits of educational attainment are even less well understood than in other more generally practised media. In public museums there is an overriding need "to deliver an interesting and stimulating message to laymen'"2

One of the essentials for good communication in a museum is to set objects within some kind of context so that specimens take their place in a coherent line of thought and do not seem to be a series of unrelated items. Without such a context, the specimens have little meaning and odd facts that are gleaned tend to be quickly forgotten; in educational terms, the exhibit would be a failure.

In two of our recent exhibitions, Man's place in evolution and Dinosaurs and their living relatives, the context for the specimens has been that of phylogeny and the fact that we chose to present phylogeny in cladistic terms has been seen by some critics as an attempt to promote cladistics at the expense of more traditional views. Recent correspondence in Nature and elsewhere emphasizes the fact that a heated debate is in progress about the relative merits of cladistic and traditional approaches to phylogeny and systematics. Exhibitions have no part in this debate between scientists, but it is clear that whichever system is used in an exhibition, one faction or another will be provoked into stern response. Accepting that one of the competing systems had to be chosen, we judged on educational grounds that cladistics was the most appropriate because of its clear and overt reasoning. Once a layman has been introduced to the system he is in a better position to understand why and how the scientists reach their conclusions. No one would pretend that the use of a cladistic system makes the study of phylogeny easy, but it can make the steps in the argument more apparent.

Some critics feel that the exhibitions should have said more about the existence of alternative systems and we are making some changes to meet that criticism, but the danger is that the exhibits in question may become displays about phylogenetic systems rather than about fossil man, or dinosaurs. A separate exhibition about systems of classification which is scheduled for future display may help to give a fuller presentation of current views.

The recent controversy has highlighted how difficult it is to maintain a balance in exhibitions between directness and fairness to every point of view - exhaustive can be exhausting to the visitor. The application of educational principles to museum exhibitions is a subject that has been sadly neglected in the past and the credibility of museums as a means of informal education has suffered in consequence. We should like to encourage serious discussion and research in this field. R.S. Mil.es

Department of Public Service, British Museum (Natural History), London, SW7, UK

\section{G.C.S. CLARKE}

1. I.ewis, B.N. Mus. J.80, 151-155 (1980). 2. Wittlin, A.S. Curator 14, 138-150 (1971)

\section{Suiting everyone}

SIR - You object most strongly (Nature 12 March, p.75) to the phrase "If the theory of evolution is true...". Having myself tried more than once to explain the work of a scientific institute in everyday language, I have some sympathy with the author of the museum guide. When all is said and done, scientific knowledge is provisional and fallible, as, implicitly, you agree. Your objection seems to be that this particular form of words gives a handle to those opponents of evolutionism whose views you regard as not "respectable", specifically to creationists. I am not a creationist and accept the evidence that evolution by natural selection has taken place, ultimately producing Man. Nevertheless I sometimes find biologists, when writing for a popular readership, to be overly dogmatic on this point. The creationist movement on this continent (which is not simply a revival of fundamentalism and obscurantism) is partly inspired, I believe, by a healthy reaction to this dogmatism.

To represent our scientific theories as final when they are not is in the long run to do our own cause a disservice, and is, in any case, dishonest. Can any evolutionist provide a clinching argument that chance mutations acted on by natural selection alone are the mechanism of evolution? I think not, and, indeed, I myself find it at least as easy to believe that there has been a purposive element in evolution. Did you really mean to imply that it is not "respectable" to believe "that the course of events may be determined by literally supernatural infuences"?

In your last paragraph, you almost seem to be proposing a noble myth, the purpose of which will be to keep all us scientists working happily at our research. If we recognize too clearly the logical status of our theories, you argue, the scientific enterprise will be undermined. But Popper's ideas, as you admit, have been around since 1934, and many branches of science have been uncommonly vigorous since then. Your argument has something in common with the old discredited argument that Christianity is socially beneficial and should be taught to the young whether it is true or false. It is this kind of argument that plays into the hands of creationists, by making more plausible their claim that evolutionism is not a scientific theory, but a kind of religion.

The most helpful ideas in this situation, I find, are not Popper's, nor dogmatism, but Kuhn's. Almost all of modern biology is "normal science" within the paradigm of Darwinism-Mendelism. Always there are some facts that do not fit a paradigm, and one day they may become so bothersome we will have to change it. In the meantime, it provides a frame of reference in which we work and by which we make sense of a wide range of data and experience. Darwinism-Mendelism is the best paradigm we have (in its field) and, as Darwin said, gives grandeur to our view of life, but it should not fight its critics by claiming, like them, to be based on divine revelation.

A.H. BAtTEN

National Research Council of Canada, Victoria, British Columbia, Canada 